\title{
Pulmonary deposition of a nebulised aerosol during mechanical ventilation
}

\author{
Simon H L Thomas, Michael J O'Doherty, Helen M Fidler, Christopher J Page, \\ David F Treacher, Thomas O Nunan
}

\begin{abstract}
Background There is increasing use of therapeutic aerosols in patients undergoing mechanical ventilation. Few studies have measured aerosol delivery to the lungs under these conditions with adequate experimental methods. Hence this study was performed to measure pulmonary aerosol deposition and to determine the reproducibility of the method of measurement during mechanical ventilation.
\end{abstract}

Methods Nine male patients were studied during mechanical ventilation after open heart surgery and two experiments were performed in each to determine the reproducibility of the method. A solution of technetium-99m labelled human serum albumin ( ${ }^{99}$ Tc HSA $(50 \mu \mathrm{g})$; activity in experiment $1,74 \mathrm{MBq}$; in experiment $2,185 \mathrm{MBq}$ ) in $3 \mathrm{ml}$ saline was administered with a Siemens Servo 945 nebuliser system (high setting) and a System 22 Acorn nebuliser unit. Pulmonary deposition was quantified by means of a gamma camera and corrections derived from lung phantom studies. Results Pulmonary aerosol deposition was completed in 22 (SD 4) minutes. Total pulmonary deposition (\% nebuliser dose (SD)) was $2.2(0.8) \%$ with $1.5 \%$ and $0.7 \%$ depositing in the right and left lungs respectively; $0.9 \%$ of the nebuliser activity was detected in the endotracheal tube or trachea and $51 \%$ was retained within the nebuliser unit. Considerable variability between subjects was found for total deposition (coefficient of variation (CV) $46 \%$ ), but within subject reproducibility was good (CV 15\%).

Conclusions Administration of aerosol in this way is inefficient and further research is needed to find more effective alternatives in patients who require mechanical respiratory support. This method of measurement seems suitable for the assessment of new methods of aerosol delivery in these patients.

(Thorax 1993;48:154-159)

Nebulised drug aerosols are administered to the lungs via the airways with the aim of producing therapeutic benefit while minimising systemic adverse effects. Use of this method is increasing in intensive therapy units and currently about a third of patients undergoing mechanical ventilation receive drugs through this route. ${ }^{1}$ The use of nebulised bronchodilators is well established; more recently other types of drug, particularly antimicrobial agents, have been administered in this way. ${ }^{2-4}$ Although deposition of nebulised aerosols has been studied in detail during normal breathing, little is known about the amount of aerosol that reaches the lungs during mechanical ventilation.

In vitro studies and animal studies performed during mechanical ventilation ${ }^{56}$ have suggested that considerable deposition of aerosol occurs in the endotracheal tube with little of the drug dose reaching the lungs. The limited human data available suggest that only $1 \cdot 2 \%-2 \cdot 9 \%$ of the nebuliser dose reaches the lungs. ${ }^{1-7}$ These studies have used ${ }^{99 m} \mathrm{Tc}$ diethylenetriaminepenta-acetate and ${ }^{99} \mathrm{~m} \mathrm{Tc}$ sulphur colloid; however, both these tracers seemed unsuitable for measuring pulmonary aerosol deposition..$^{8-10}$ Colloidal ${ }^{99 m} \mathrm{Tc}$ human serum albumin ( ${ }^{99 \mathrm{~m}}$ Tc HSA) appeared more appropriate $^{9-12}$ and the validity and reproducibility of measurements made with this marker during spontaneous respiration have been reported. ${ }^{13}$

The aims of our study were to apply the ${ }_{99 m}$ Tc HSA marker technique to the measurement of pulmonary deposition of aerosol during mechanical ventilation in a group of patients with apparently healthy lungs after open heart surgery. The study had two main arms: firstly, to measure the deposition efficiency of an inspiratory phase activated jet nebuliser system with equipment that has not been: studied before though it is commonly used in intensive care units; secondly, to determine the immediate reproducibility of these measurements of aerosol deposition.

\section{Methods}

The study was approved by the ethics committee of West Lambeth Health District. Patients about to undergo elective open heart surgery were invited to participate and all those taking part gave informed written consent. Those patients with pre-existing respiratory symptoms or disease were excluded as the intention of the study was to measure aerosol deposition in patients with normal lungs. Lung function (forced expiratory volume in one second $\left(\mathrm{FEV}_{1}\right)$, forced vital capacity (FVC), peak expiratory flow (PEF)) was measured before surgery. Experimental studies were performed within a few hours of the open heart surgery in those patients who 
still required mechanical ventilation at that time. The decision on the duration of ventilation was made on clinical grounds by medical staff who were not involved in the study and only a few of those who gave informed written consent were eventually studied.

All the patients were intubated and were ventilated with a Siemens Servo 900C mechanical ventilator in volume control mode. The position of the endotracheal tube was verified from a chest $x$ ray film. Ventilator settings were made on the basis of the patient's clinical requirements and were not altered during the study. Arterial blood gas analysis was performed in all patients immediately before the study.

Pulmonary aerosol deposition was measured by a modification of a technique designed for spontaneously breathing subjects and described in detail elsewhere. ${ }^{13-15}$ Before administration of aerosol a xenon-133 ( ${ }^{133} \mathrm{Xe}$ ) a breath hold image was obtained to define the lung edges and regions. This was achieved by injection of $10 \mathrm{ml}(200 \mathrm{MBq})$ of the gas into a port on the catheter mount connection at the proximal end of the endotracheal tube (fig 1) immediately before inflation of the lungs. Ventilation was stopped for 10 seconds as soon as the lungs were filled and an anterior ventilation image was acquired over this period with a gamma camera linked to a computer. Ventilation was then resumed. Expired ${ }^{133} \mathrm{Xe}$ was collected in a Douglas bag from the expiration outlet of the ventilator until washout was complete.

Administration of aerosols produced by jet nebulisers to patients undergoing volume cycled mechanical ventilation requires that the jet nebuliser is driven by gas during lung inflation only (inspiratory phase nebuliser activation). The volume of the gas used for this must be taken into account when the tidal volume is set. In these studies this was achieved with a Siemens 945 Servo nebuliser driver (high flow setting) linked to a System 22 Acorn nebuliser (Medic-Aid Ltd, UK) that was connected to the catheter mount and endotracheal tube (fig 1). This nebuliser driver pumps gas at the set oxygen concentration into the ventilator circuit through the nebuliser. The resulting increase in expired respiratory minute volume is detected by a sensor in the ventilator and allows appropriate adjustment of the preset respiratory minute volume.

Two studies of aerosol deposition were

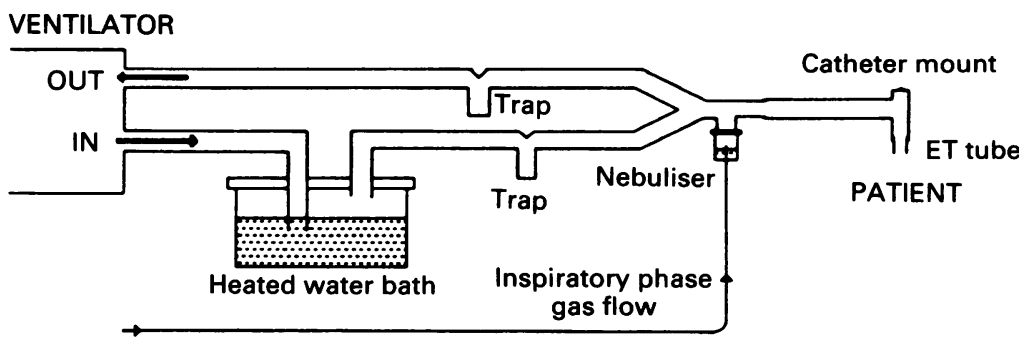

Figure 1 Ventilator circuit and nebuliser apparatus. ET-endotracheal tube. performed on each patient. The first study (experiment 1) was performed with a nebuliser solution of $74 \mathrm{MBq}{ }^{99 m}$ Tc HSA $(50 \mu \mathrm{g})$ in $3 \mathrm{ml}$ saline. During the 30 minute period of administration of aerosol the appearance of ${ }^{99 m}$ Tc HSA in the lungs was monitored continuously (anterior projection) with a portable gamma camera (small field of view with diverging collimator) in 15 second counting frames. After aerosol administration $300 \mathrm{sec}-$ ond static scans were taken of the lungs (posterior and anterior projections) and from these the geometric mean intrapulmonary activity was calculated..$^{13}$ The posterior view was obtained by scanning the lungs from underneath through the bed. Activity in the nebuliser was measured with the gamma camera before and after nebulisation.

Experiment 2 was performed immediately after completion of experiment 1. Identical nebulisation equipment, ventilator settings, and experimental methods were used except that on this occasion the nebuliser solution contained $185 \mathrm{MBq}{ }^{99 m} \mathrm{Tc}$ HSA activity. Activity detected in the chest after experiment 1 was subtracted from that measured after experiment 2 .

Absolute pulmonary deposition of the nebulised aerosol, expressed as a percentage of the initial nebuliser dose, was estimated by a modification of the lung phantom method described by Newman et al. ${ }^{16}$ Preliminary experiments were performed on three patients to measure their anteroposterior chest tissue attenuation by means of a $30 \mathrm{~cm}$ diameter ${ }^{57} \mathrm{Co}$ flood source as previously described. ${ }^{13}$ These experiments indicated that their tissue attenuation was similar to that produced by a $16 \mathrm{~cm}$ thickness of mix-D tissue equivalent material. This figure was similar to that found in a larger group of healthy subjects. ${ }^{13}$ To correct for tissue attenuation a piece of absorbent paper uniformly soaked with $74 \mathrm{MBq}{ }^{99 m} \mathrm{Tc}$ was imaged directly on the collimator face and then anterior and posterior (from beneath the bed) scans of this phantom were taken with an $8 \mathrm{~cm}$ thickness of mix-D (half of the tissue attenuation estimated in the preliminary studies) placed between it and the camera for each view. The same ${ }^{99 \mathrm{~m}} \mathrm{Tc}$ activity was also placed within a nebuliser and measured on the camera. From the ratio of counts detected in the nebuliser and counts detected in the anterior and posterior phantom views it is possible to calculate a correction factor for each view that relates activity detected in the phantom to activity within the nebuliser unit. This same correction factor was applied for each patient in the study. This was considered appropriate because it was impractical to make individual measurements in these patients and because our previous study had shown that the use of individually measured correction factors only reduced the intersubject variability in pulmonary deposition measurements by a small and statistically non-significant amount. ${ }^{13}$ The distribution of deposited aerosol within the lung was studied by calculating the ratios of peripheral to central and upper to lower 
Table 1 Details of the nine patients studied

\begin{tabular}{|c|c|c|}
\hline & \multicolumn{2}{|l|}{ Patient details } \\
\hline & Mean (SD) & Range \\
\hline \multicolumn{3}{|l|}{ Preoperative assessment: } \\
\hline Age $(y)$ & $57(7)$ & $(46-66)$ \\
\hline Height (m) & $1.76(0.04)$ & $(1 \cdot 70-1 \cdot 80)$ \\
\hline Weight (kg) & $89(11)$ & $(68-103$ \\
\hline $\mathrm{FEV}_{1}(\mathrm{l})$ & $3 \cdot 11(0 \cdot 88)$ & $(2 \cdot 03-4 \cdot 15)$ \\
\hline FVC (1) & $3.43(1.05)$ & $(2 \cdot 08-4 \cdot 15)$ \\
\hline $\operatorname{PEF}\left(1 \min ^{-1}\right)$ & $526(100)$ & $(422-622)$ \\
\hline \multicolumn{3}{|l|}{ Postoperative state: } \\
\hline $\mathrm{FIO}_{2}(\%)$ & $59(14)$ & $(30-80)$ \\
\hline $\mathrm{pH}$ & $7.45(0.06)$ & $(7 \cdot 35-7 \cdot 54)$ \\
\hline $\mathrm{PO}_{2}(\mathrm{kPa})$ & $18 \cdot 0(5 \cdot 7)$ & $(11 \cdot 6-27 \cdot 6)$ \\
\hline $\mathrm{PCO}_{2}(\mathrm{kPa})$ & $5 \cdot 2(0 \cdot 6)$ & $(4 \cdot 4-5 \cdot 9)$ \\
\hline Ventilation rate (breaths $/ \mathrm{min}$ ) & $13(1)$ & $(12-15)$ \\
\hline Respiratory minute volume ( $\left.\mathrm{min}^{-1}\right)$ & $9 \cdot 1(1 \cdot 3)$ & $(6 \cdot 8-11 \cdot 2)$ \\
\hline Inspiratory time $(\%)$ & $30(4)$ & $(25-33)$ \\
\hline Pause time $(\%)$ & $17(5)$ & $(10-20)$ \\
\hline
\end{tabular}

$\mathrm{FEV}_{1}$ - forced expiratory volume in one second; FVC - forced vital capacity; PEF-peak expiratory flow; $\mathrm{FIO}_{2}$ - fractional inspired oxygen; $\mathrm{PO}_{2}$ - partial pressure of oxygen; $\mathrm{PCO}_{2}-$ partial pressure of carbon dioxide.

zone ${ }^{99 m} \mathrm{Tc}$ activity. Each ratio was then divided by a similar ratio obtained from the ${ }^{133} \mathrm{Xe}$ scan to correct for regional ventilation. Values less than unity indicate preferential deposition in the central or lower lung zones.

The reproducibility of the measurements of aerosol deposition was determined by a two way (subjects and experiments) repeated measures analysis of variance and calculation of the coefficient of variation (CV) (within and between subjects) as the square root of the appropriate mean square value divided by the mean deposition for both experiments combined. The method of Bland and Altman was also used. ${ }^{17}$

Results

Studies were performed on nine men. Table

Table 2 Radioaerosol distribution $(n=9)$

\begin{tabular}{|c|c|c|c|c|}
\hline & \multicolumn{2}{|l|}{ Deposition (\%) } & \multicolumn{2}{|l|}{$C V(\%)$} \\
\hline & $\begin{array}{l}\text { Experiment } 1 \\
\text { Mean (SD) }\end{array}$ & $\begin{array}{l}\text { Experiment } 2 \\
\text { Mean (SD) }\end{array}$ & $\begin{array}{l}\text { Between } \\
\text { subjects }\end{array}$ & $\begin{array}{l}\text { Within } \\
\text { subjects }\end{array}$ \\
\hline \multicolumn{5}{|l|}{ Pulmonary deposition } \\
\hline Both lungs & $2 \cdot 28(0.84)$ & $2 \cdot 12(0.69)$ & 46 & 15 \\
\hline Right lung & $1.54(0.70)$ & $1.39(0.69)$ & 63 & 20 \\
\hline Central & $0.31(0.17)$ & $0.27(0.15)$ & 75 & 32 \\
\hline Peripheral & $1.08(0.50)$ & $0.84(0.35)$ & 52 & 17 \\
\hline Upper & $0.30(0 \cdot 16)$ & $0.22(0.15)$ & 78 & 66 \\
\hline Lower & $0.49(0.26)$ & $0.37(0.13)$ & 49 & 57 \\
\hline Left lung & $0.75(0.30)$ & $0.73(0.32)$ & 57 & 5 \\
\hline Central & $0 \cdot 10(0 \cdot 10)$ & $0.14(0.20)$ & 143 & 72 \\
\hline Peripheral & $0.56(0.21)$ & $0.51(0.23)$ & 57 & 20 \\
\hline Upper & $0.16(0.06)$ & $0.18(0.12)$ & 73 & 23 \\
\hline Lower & $0.24(0.13)$ & $0.22(0.13)$ & 75 & 25 \\
\hline \multicolumn{5}{|l|}{ Extrapulmonary deposition } \\
\hline Tracheal/endotracheal tube & $0.88(0.51)$ & $1 \cdot 12(0 \cdot 79)$ & 74 & 50 \\
\hline Exhalation filter & $11 \cdot 1(2 \cdot 7)$ & $11 \cdot 8(1 \cdot 8)$ & 26 & 11 \\
\hline Nebuliser retention & $51 \cdot 5(8 \cdot 1)$ & $47 \cdot 8(7 \cdot 4)$ & 19 & 15 \\
\hline Unaccounted (tubing) & $34 \cdot 1(8 \cdot 9)$ & $37 \cdot 2(9 \cdot 0)$ & 33 & 24 \\
\hline \multicolumn{5}{|c|}{ Deposition ratios $\left({ }^{133} \mathrm{Xe} \text { corrected }\right)^{\star}$} \\
\hline Peripheral:central & $0.54(0.19)$ & $0.51(0.23)$ & 53 & 12 \\
\hline Upper:lower & $1.40(0.58)$ & $1.22(0.68)$ & 60 & 30 \\
\hline Time to plateau (min) & $23 \cdot 4(7 \cdot 4)$ & $22 \cdot 4(4 \cdot 5)$ & 24 & 9 \\
\hline
\end{tabular}

*Values greater than 1 indicate preferential deposition in the peripheral or upper lung zones. All differences between experiments were non-significant by paired $t$ tests.

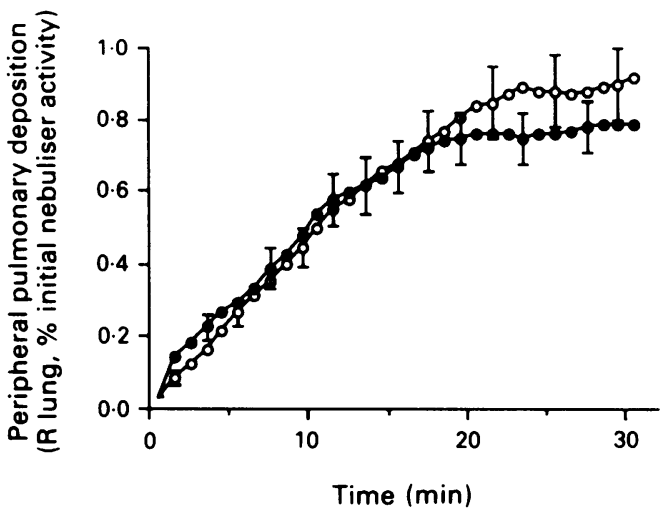

Figure 2 Dynamic deposition of radioaerosol in right peripheral lung during nebulisation. Open circles experiment 1; closed circles experiment 2. Results are mean and $S E$ values.

1 shows their clinical details, including their preoperative lung function and ventilation conditions after operation. Three were smokers and six were ex-smokers. All had undergone coronary artery bypass graft surgery and were intubated with 8 or $9 \mathrm{~mm}$ cuffed endotracheal tubes.

Figure 2 shows the dynamic aerosol deposition. For each experiment deposition was completed within the 30 minute period of study and the mean time for completion (time to plateau) was 23 minutes for experiment 1 and 24 minutes for experiment 2 .

Figure 3 presents examples of representative ${ }^{133} \mathrm{Xe}$ ventilation and ${ }^{99 \mathrm{~m}} \mathrm{Tc}$ HSA deposition scans. These show poor ventilation and deposition of aerosol in the left lung. This pattern was found in six of the patients; in one patient ventilation and deposition in the right lung was poor. Substantial deposition of aerosol was found around the lower part of the endotracheal tube.

Quantification of aerosol deposition showed that only $3 \cdot 2 \%$ of the initial nebuliser dose reached the patient's respiratory tract. Of this, $1 \%$ was deposited in the endotracheal tube or trachea and only $2 \cdot 2 \%$ reached the lungs (table 2). Most of the nebuliser solution was retained within the nebuliser unit or was deposited in the nebuliser connection or catheter mount; $11.5 \%$ of the aerosol was deposited in the exhalation port filter; and $32 \%$ of the initial nebuliser activity was not accounted for, presumably because of deposition within the ventilator circuit. It was not possible to verify this directly because of the size of the circuit-several metres of semirigid tubing, two traps, and a large heated water bath-and because of the difficulty in making a reliable correction for the geometric distribution of counts.

Deposition of aerosol in various lung regions (expressed as corrected counts) and deposition ratios of peripheral:central lung and upper:lower lung (each corrected for regional lung ventilation from similar ratios collected from the ${ }^{133} \mathrm{Xe}$ scan) indicated preferential deposition of aerosol in the central and upper lung regions (table 2).

Table 2 shows the repeatability of the 

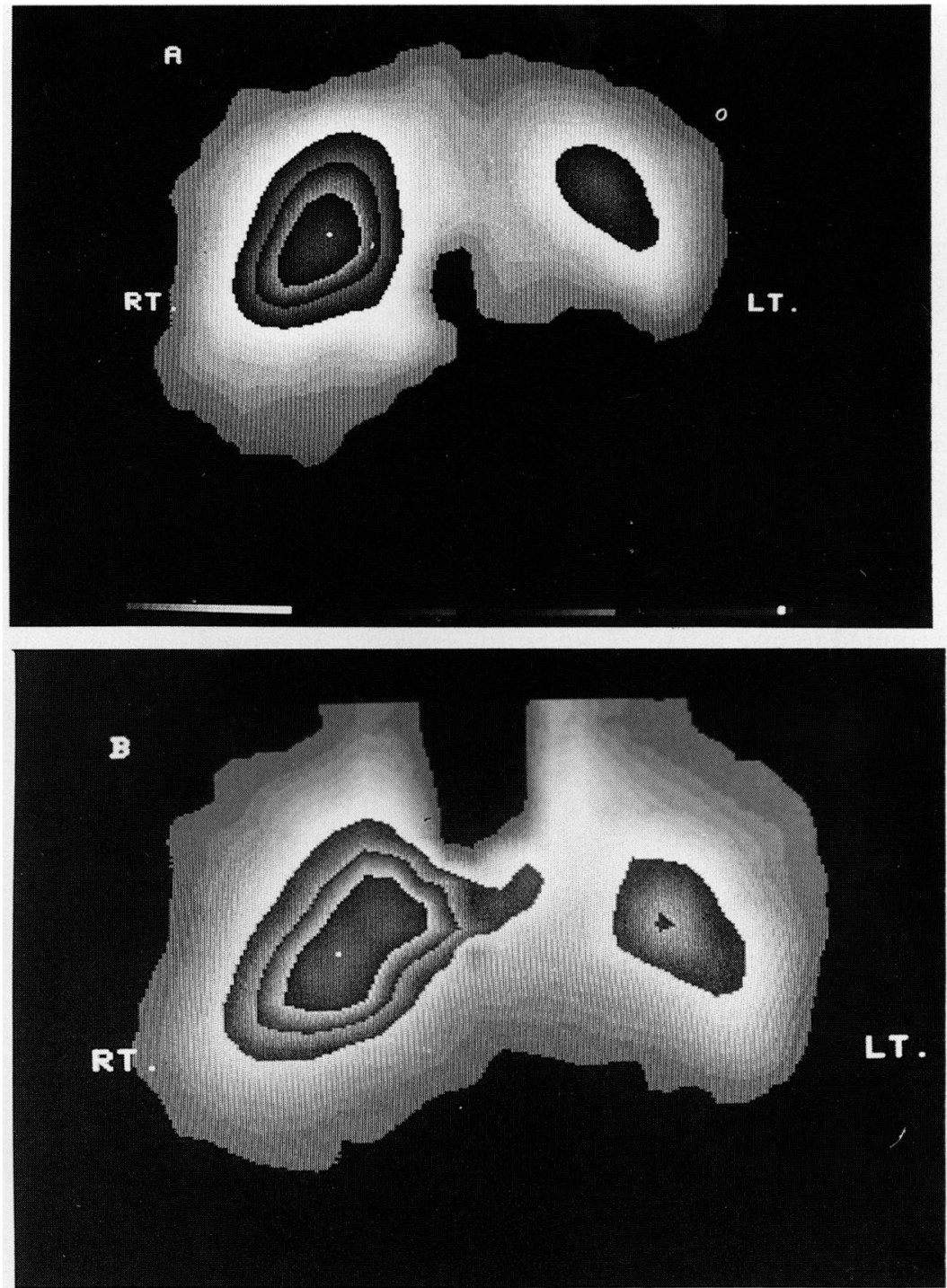

Figure 3 Examples of representative ${ }^{133} \mathrm{Xe}$ breath hold $(A)$ and ${ }^{99 m} \mathrm{Tc}$ deposition $(B)$ scans from the same subject. In scan $B$ the mediastinum and endotracheal tube areas have been masked to improve definition of the lungs.
$95 \%$ limits of agreement of 0.65 and +1.68 -that is, $95 \%$ of experiment 1 values were from 0.65 to 1.68 times the corresponding experiment 2 values. Corresponding limits of agreement for nebuliser output were $0 \cdot 70$ and $1 \cdot 22$ with a mean bias of 0.92 .

\section{Discussion}

The effectiveness of nebulised drug treatment during mechanical ventilation is expected to depend in part on the efficiency of drug deposition in the lungs. Inconsistent drug delivery may explain why some studies have found nebulised drugs to be effective under these conditions ${ }^{18-20}$ whereas others have not. ${ }^{17}$ The two previous attempts to measure aerosol deposition during mechanical ventilation have been inadequate because they have used inappropriate radionuclide tracers and suboptimal imaging techniques. Fuller et al ${ }^{1}$ used a ${ }_{99 \mathrm{~m}} \mathrm{Tc}$ sulphur colloid tracer and estimated pulmonary deposition from a Bennett twin jet nebuliser to be $1 \cdot 2 \%$. A large proportion of this tracer becomes attached, however, to the plastic tubing of the ventilator circuit and the amount of a therapeutic drug reaching the lung may be underestimated by as much as three times with this method. ${ }^{10}$ MacIntyre et

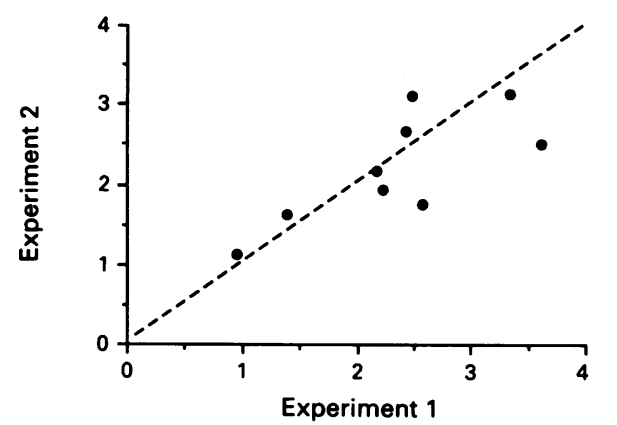

experiments, obtained by comparison of results of experiment 1 and experiment 2 for each patient and expressed as within subject $\mathrm{CV}$. Figure 4 presents individual results for total pulmonary deposition. Although there was considerable variability between subjects, the within subject variability was comparable with the variability in nebuliser radioaerosol output for deposition in the lungs as a whole and for the peripheral lung regions. Within subject variability was greater for deposition in the smaller lung regions and for the tracheal region. Analysis of variability ${ }^{17}$ was performed for total pulmonary deposition (fig 4). There was no significant bias between experiments (experiment 1-experiment 2, $\mathrm{d}=0.16 \%, 95 \%$ confidence interval, (95\% CI) -0.25 to $+0.58 \%$ ) and the $95 \%$ limits of agreement (with their $95 \% \mathrm{CIs}$ ) were -0.94 $(-1.91$ to 0.03$)$ and $1.26(0.29$ to 2.23$) \%$. As the discrepancy may increase in relation to the mean value for the two experiments (fig 4, middle panel) a similar analysis was performed on log transformed data (fig 4 , lower panel). This showed a mean bias of 1.05 with

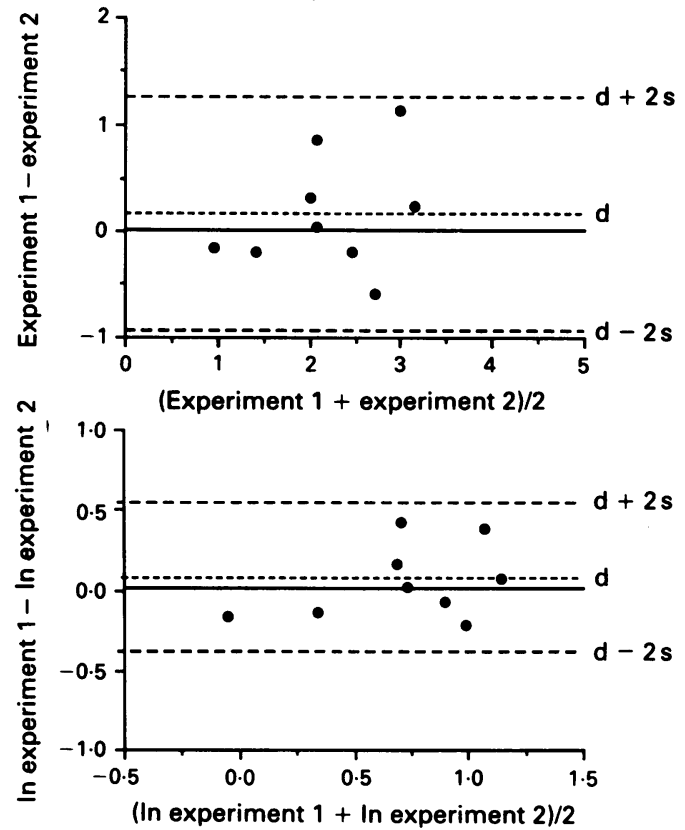

Figure 4 Comparison of total pulmonary deposition (\% initial nebuliser dose) after experiments 1 and 2. Top panel simple comparison; middle panel Bland-Altman analysis of agreement; ${ }^{17}$ lower panel Bland-Altman analysis of log transformed data. 
$a l^{7}$ estimated deposition to be $2 \cdot 8 \%$ from a ${ }_{99 \mathrm{~m}} \mathrm{Tc}$ diethylenetriaminepenta-acetate marker. This marker may also underestimate lung deposition as it is rapidly removed from the lungs into the bloodstream. Furthermore some of the activity may have been in the pulmonary blood pool rather than in the air passages, introducing further error. In neither study were both anteroposterior and posteroanterior scans taken for the determination of geometric mean counts. This will lead to further inaccuracy if the front to back distribution of pulmonary activity is uneven.

The marker used in our experiments is more suitable for deposition work because it is not removed from the lungs by passage into the bloodstream and remains at its site of deposition for several hours before removal by mucociliary clearance. This process is slow and no corrections are required to take it into account. The behaviour of the tracer in the aerosol seems to mimic that of therapeutic drugs $^{9-11}$ and its addition does not alter particle sizes significantly. ${ }^{113}$ We have used the geometric mean count to obtain estimates of pulmonary deposition. Our lung phantom, used to correct deposition data for tissue attenuation and geometric errors, was shown in preliminary studies to be associated with attenuation similar to that in our patients and this phantom method of correction estimates actual intrapulmonary activity to within $6 \% .^{21}$

With these methods we have confirmed that aerosol delivery is poor during mechanical ventilation. The lung deposition of $2 \cdot 2 \%$ found here is much less than the $5 \%$ deposition measured with both the same methods and nebuliser during spontaneous breathing, but is consistent with the delivery of $4 \%-5 \%$ through an endotracheal tube in in vitro models. ${ }^{22}{ }^{23}$ Deposition varied widely between patients, as has been found in subjects breathing normally, ${ }^{13}$ but immediate reproducibility within the same patient was good. The distribution of deposition within the lungs was similar to that previously found in supine subjects breathing spontaneously; increased aerosol was deposited in the upper lungs. ${ }^{14}$ The ratio of central to peripheral deposition was reduced compared with results obtained during spontaneous respiration. It is possible that larger aerosol particles impact on the ventilator tubing or endotracheal tube and do not reach their usual site of deposition in the larger bronchi. Increased central deposition is seen in patients with airflow obstruction ${ }^{24}$ and in view of their need for inhaled bronchodilators further studies in this group would be of interest. It is not clear why the ventilation and deposition in the left lung were so poor after open heart surgery. It is possible that this was due to manipulation of the lung during surgery. Alternatively the inspiratory air flow may have been preferentially directed into the right main bronchus by the endotracheal tube, although its position was confirmed radiologically in each case. Studies after other types of surgery would be of interest.

The output of this nebuliser was about
$50 \%$ during mechanical ventilation, similar to the output in spontaneously breathing subjects. ${ }^{13}$ Thus a reduction in nebuliser output is not the explanation for the poor deposition. Instead it seems that a substantial proportion of the aerosol is deposited on the ventilator tubing and endotracheal tube, as described by others. ${ }^{1562225}$ Inspiratory phased nebuliser actuation as used here might be expected to increase aerosol delivery to the lungs by reducing the inevitable wastage of the aerosol during expiration. ${ }^{26}$ Observation of the nebuliser suggests that this does not happen because there is a delay between its actuation and the production of aerosol. As a result most of the aerosol is produced too late in the inspiratory period to be carried to the lungs. Instead it is lost down the expiratory limb of the ventilator circuit during the subsequent expiratory phase. Improved delivery is obtained by continuous nebulisation ${ }^{27}$ but this is incompatible with volume cycled ventilation.

Several ways of improving aerosol delivery during mechanical ventilation have been suggested. These include use of nebulisers producing submicronic particles, which are less likely to deposit on the tubing ${ }^{56}$; increasing the volume of nebuliser solution and thus the drug output of the nebuliser ${ }^{13}{ }^{23}$; changing the ventilator settings to increase the inspiratory ${ }^{23}$ or pause times; altering the position of the nebuliser in the ventilator circuit ${ }^{2326}$ or the length of tubing between nebuliser and patient ${ }^{25}$; or making use of large capacity ultrasonic nebulisers ${ }^{23}$ or pressurised metered dose inhalers, with $^{27}$ or without ${ }^{1}$ spacer attachments. None of these techniques has yet been compared in vivo by adequate experimental methods. The method described here seems suitable for such studies because it uses an adequate tracer and method of estimating intrapulmonary activity and because paired measurements can be made in the same patient within a short time with acceptable repeatability. This is important as it allows patients to be studied with different nebuliser arrangements before their clinical state changes. In view of the poor aerosol delivery found with current methods of aerosol administration under these conditions, such studies are urgently required.

We thank Valerie Arnold and Heather Bowen for technical assistance and the staff of Mead ward, St Thomas's Hospital, for their help and cooperation with the study. We are particularly grateful to Mr B T Williams, Mr G Venn, Dr C Apps, Dr T Hunt, and Dr R Linton for allowing us to study their patients and for their cooperation with the research. This work was supported by a grant from the Intensive Care Society.

1 Fuller HD, Dolovich MB, Posmituck G, Wong Pack W, Newhouse MT. Pressurised aerosol versus jet aerosol delivery to mechanically ventilated patients. Comparison of dose to the lungs. Am Rev Respir Dis Comparison of dose

2 Stoutenbeek CP, van Saene HK, Miranda DR, Zandstra DF, Langrehr D. Nosocomial gram-negative pneumonia in critically ill patients. A 3 year experience with a novel therapeutic regimen. Intensive Care Med 1986;12:419-23.

3 Frankel LR, Wilson CW, Demers RR, Parker JR. Lewiston NJ, Stevenson DK, et al. A technique for thi 
administration of ribavirin to mechanically ventilated infants with severe respiratory syncytial virus infection. Crit Care Med 1987;15:1051-4

4 Girard PM, Clair B, Certain A, Bidault R, Matheron S, Regnier B, et al. Comparison of plasma concentrations of aerosolised pentamidine in nonventilated and ventilated patients with Pneumocystosis. Am Rev Respir Dis 1989;140:1607-10.

5 Ahrens RC, Ries RA, Popendorf W, Wiese JA. The delivery of therapeutic aerosols through endotracheal tubes. Pediatr pulmonol 1986;2:19-26.

6 Flavin M, MacDonald M, Dolovich M, Coates G, O'Brodovich $\mathrm{H}$. Aerosol delivery to the rabbit lung with an infant ventilator. Pediatr Pulmonol 1986;2:35-9.

7 MacIntyre NR, Silver RM, Miller CW, Schuler F, Coleman RE. Aerosol delivery in intubated, mechanically ventilated patients. Crit Care Med 1985;13:81-4.

8 Thomas SHL, Langford JA, George RDG, Geddes DM Aerosol deposition in the human lung: effect of high-frequency oscillation on the deposition characteristics of an inhaled nebulised aerosol. Clin Sci 1988;75:535-42.

9 Smaldone GC, Perry RJ, Deutsch DG. Characteristics of nebulizers used in the treatment of AIDS related Pneumocystis carinii pneumonia. Fournal of Aerosol Medicine 1988;1:113-26.

10 O'Riordan TG, Greco MJ, Perry RJ, Smaldone GC. Nebulizer function during mechanical ventilation. $\mathrm{Am}$ Nebulizer function during mecha
Rev Respir Dis 1992;145:1117-22.

11 O'Doherty MJ, Thomas SHL, Page C, Clarke AR, Mitchell D, Heduan E, et al. Does ${ }^{99 \mathrm{~m}} \mathrm{Tc}$ human serum albumin alter the characteristics of nebulised pentamidine isethionate? Nucl Med Commun 1989;10:523-9.

12 Perry RJ, O'Riordan TG, Smaldone GC. Inaccuracies in measurements of nebulized drug delivery. Am Rev Respir Dis 1991;143:A708.

13 Thomas SHL, O'Doherty MJ, Page CJ, Nunan TO. Variability in the measurement of nebulised aerosol deposition in man. Clin Sci 1991;12:767-75.

14 O'Doherty MJ, Thomas SHL, Page CJ, Bradbeer C, Nunan TO, Bateman NT. Does inhalation of pentamidine in the supine position increase deposition in the upper part of the lung? Chest 1990;97:1343-8.

15 O'Doherty M, Thomas S, Page C, Bradbeer CS, Nunan $T$, Bateman N. Pulmonary deposition of nebulised pentamidine. The effect of nebuliser type, dose and volume of fill. Thorax $1990 ; 45: 460-4$.

16 Newman SP, Woodman G, Clarke SW. Deposition of carbenicillin aerosols in cystic fibrosis: effects of nebuliser system and breathing pattern. Thorax 1988;43. 318-22.

17 Bland JM, Altman DG. Statistical methods for assessing agreement between two methods of clinical measurement. Lancet 1986;i:307-10.

18 Gay PC, Rodarte JR, Tayyab M, Hubmayr RD Evaluation of bronchodilator responsiveness in mechanically ventilated patients. $A m$ Rev Respir Dis 1987; 136:880-5.

19 Wegener $T$, Wretman $S$, Sandhagen B, Nystrom SO Effect of ipratropium bromide aerosol on respiratory function in patients under ventilator treatment. Acta Anaesthesiol Scand 1987;31:652-4.

20 Legare M, Petrof B, Simkovitz P, Goldberg P, Gottfried $\mathrm{S}$. Aerosolised ipratopium bromide in mechanically ventilated COPD patients (abstract). Am Rev Respir Dis 1988;137:60.

21 Forge NI, Mountford PJ, O'Doherty MJ, Coakley AJ. A comparison of quantification techniques in planar radionuclide lung imaging (abstract). Nucl Med Commun 1991;12:296.

22 Fraser I, DuVall A, Dolovich $M$, Newhouse MT. Therapeutic aerosol delivery in ventilator systems. $A m$ Rev Respir Dis 1981;123:107.

23 O'Doherty MJ, Thomas SHL, Fidler HM, Page CJ, Treacher DF, Nunan TO. Delivery of a nebulised aerosol to a lung model during mechanical ventilation. Effect of ventilator settings and nebuliser type, position, and volume of fill. Am Rev Respir Dis 1992;146:383-8.

24 Vezina W, Chamberlain M, Vinitski S, King $M$ Nicholson R, Morgan WK. Radioaerosol ventilation imaging in ventilator-dependent patients. Technical considerations. Clin Nucl Med 1985;10:759-66.

25 Kim CS, Eldridge MA, Sackner MA. Delivery efficiency of aerosols in intubated subjects. Am Rev Respir Dis 1984;129:A110.

26 Hughes JM, Saez BS. Effects of nebulizer mode and position in a mechanical ventilator circuit on dose efficiency. Respiratory Care 1987;32:1131-5.

27 Simonds AK, Newman SP, Cox D, Clarke SW. Aerosol delivery during mechanical ventilation: nebuliser or nebuhaler (abstract). Thorax 1990;45:315P. 